\title{
Treatment with inhaled corticosteroids in chronic obstructive pulmonary disease
}

\author{
Christer Janson \\ Department of Medical Sciences: Respiratory, Allergy and Sleep Research, Uppsala University, Uppsala, Sweden \\ Correspondence to: Christer Janson. Department of Medical Sciences: Respiratory, Allergy and Sleep Research, Uppsala University, Uppsala, Sweden. \\ Email: christer.janson@medsci.uu.se.
}

\begin{abstract}
In chronic obstructive pulmonary disease (COPD), treatment with inhaled corticosteroids (ICSs) in combination with long acting beta-2-agonists (LABA) or LABA/long-acting muscarinic antagonists (LAMA) is used in order to reduce exacerbations. Treatment with ICS is, however, associated with side effects such as oropharyngeal candidiasis, skin thinning or easy bruising and pneumonia. The aim of this review was to investigate when to use ICS in COPD and to compare the effectiveness and safety of different ICSs. Studies comparing the effect of ICS/LABA and LABA/LAMA on exacerbations have shown divergent results, whereas most studies comparing ICS/LABA/LAMA (triple therapy) with LABA/LAMA have reported fewer exacerbations with triple therapy. Several investigations have shown that the number of eosinophils in blood predicts whether a patient will benefit from treatment with ICS. There is also data indicating that ICS has a small but significant positive effect on lung function decline and decrease mortality. There are four observational studies showing a better effect on exacerbations with budesonide/formoterol than fluticasone propionate/salmeterol and three observational studies showing less risk of pneumonia with budesonide than fluticasone propionate. Studies comparing the effect and safety of other ICSs such as fluticasone furoate and beclomethasone are too few to draw firm conclusions from. In conclusion, ICS together with LABA or LABA/LAMA reduces the risk of exacerbations in COPD. The indication of using ICS in COPD is stronger if the patient has increased blood eosinophils levels. There are data indicating that the choice of ICS matters, with studies showing a better effect-safety profile with budesonide compared to fluticasone propionate whereas it is not possible to make benefit-risk comparisons between the other licensed ICSs.
\end{abstract}

Keywords: Chronic obstructive pulmonary disease (COPD); inhaled corticosteroids (ICSs); eosinophils

Submitted Dec 16, 2019. Accepted for publication Feb 13, 2020.

doi: $10.21037 /$ jtd.2020.02.51

View this article at: http://dx.doi.org/10.21037/jtd.2020.02.51

\section{Introduction}

Chronic obstructive pulmonary disease (COPD) is a common disorder, which has a large negative effect on health-related quality of life (1) and causes a large burden for the individual patient and the society as a whole (2). COPD is globally the third leading cause of mortality (3) and in Sweden it has been estimated that COPD patients on average live 8 years shorter than aged matched persons without COPD (4).

COPD is characterised by chronic airflow obstruction.
In the GOLD guidelines, airflow obstruction is defined as a ratio between forced expiratory volume in one second $\left(\mathrm{FEV}_{1}\right)$ and forced vital capacity (FVC) that is below 0.7 after bronchodilation (5). The Burden of Obstructive Lung Disease (BOLD) study showed that globally $10-20 \%$ of the population that are 40 years or older have a spirometry that fulfils this criterion for COPD (6). A problem, however, is that $80 \%$ of these individuals have not been diagnosed (7). There is also the opposite problem. In the BOLD study, half of those diagnosed as having COPD did not fulfil the spirometric criteria for the disease (8). 
The underlying cause for the lung impairment in COPD is airway inflammation and destructive structural changes (9). This inflammation includes both the innate and adaptive immune system and many kinds of cells such as neutrophils, macrophages and lymphocytes. Lately it has become clear that the eosinophil granulocyte also is an important player in the inflammatory pattern of COPD (10). Even though inflammation is an underlying mechanism in COPD, the role of anti-inflammatory treatment with inhaled corticosteroids (ICSs) is much more limited in COPD (5) than it is for asthma (11).

The aim of this review was to investigate when ICS should be used in COPD and also to compare different ICSs when it comes to effectiveness and safety in COPD treatment.

\section{Methods}

This is a narrative review investigating the effect of ICS in COPD. The focus of the review is on five topics:

(I) The effect of ICS in combination with long acting $\beta 2$-agonists (LABA) or LABA/long acting muscarinic antagonists (LAMA) on exacerbations;

(II) The predictive value of measuring blood eosinophil (B-Eos) levels on the effectiveness of ICS in COPD;

(III) The effect of ICS on lung function decline and mortality in COPD;

(IV) Interclass difference between ICSs in effectiveness and safety in COPD;

(V) Does the benefit of using ICS outweigh the negative side effects?

\section{Results}

\section{Treatment with ICS in COPD}

Treatment with ICS in combination with LABA or LABA/ LAMA is in COPD mainly used in order to reduce the risk of exacerbations (12). It should, however, be noted that treatment with ICS in COPD may have other positive effects such as increasing health-related quality of life $(13,14)$, improving dyspnoea (14) and sleep $(15,16)$. There are also studies suggesting that COPD patients using ICS have a lower risk of cardiovascular disease (17) and lung cancer $(18,19)$ than COPD patients not using ICS. Treatment with ICS is, however, also associated with sideeffects, where the most established ones are oropharyngeal candidiasis, skin thinning or easy bruising (20) and pneumonia (21-24). Other possible but less established side effects are cataract, diabetes and osteoporosis (20). These side-effects together with the fact that treatment with LAMA or LABA/LAMA to some extent also reduce the risk of exacerbations $(25,26)$ have led to the use of ICS in COPD being questioned (27).

\section{Studies comparing ICS/LABA with LABA, LAMA or $L A M A+L A B A$}

Adding an ICS to a LABA has repeatedly been shown to improve airflow limitation, quality of life, and exacerbation rates compared with use of a LABA alone in randomised controlled trials (RCT) $(13,28,29)$. Treatment with ICS/LABA and LAMA was studied in one RCT. No difference in exacerbation rate was found when treatment with fluticasone propionate/salmeterol (FP/SALM) and tiotropium was compared (30). There was, however, a significantly lower rate of exacerbations requiring systemic corticosteroids, lower mean St George Respiratory Questionnaire score (better health-related quality of life) and lower mortality in the FP/SALM group.

Patients treated with LABA/LAMA (indacaterol/ glycopyrronium) had a lower incidence of exacerbations than patients treated with FP/SALM in two RCTs $(31,32)$. Recently, however, two studies have shown the opposite results with ICS/LABA being superior to LABA/LAMA in term of exacerbations $(14,33)$. Differences in patient selection may be an explanation to these diverging results. Another explanation may be differences in the intrinsic activity of the molecules used in the studies. FP was the ICS used in the studies showing superiority for LABA/ LAMA while fluticasone furoate and budesonide (BUD), respectively were used in the two studies showing a better effect of ICS/LABA.

\section{Triple therapy}

Combining all three classes of drugs (ICS/LABA/ LAMA), so called triple therapy, has been investigated in many studies. In two studies patients treated with BUD/ formoterol (FORM) + tiotropium had less exacerbations than patients treated with tiotropium alone $(34,35)$. No difference in exacerbation rate was found between treatment with FP/SALM + tiotropium vs. tiotropium in two other RCTs although a benefit for triple therapy compared to LAMA was found for other outcome variables $(36,37)$. 
Table 1 Blood eosinophils (B-Eos) as biomarker for predicting response to ICS in COPD

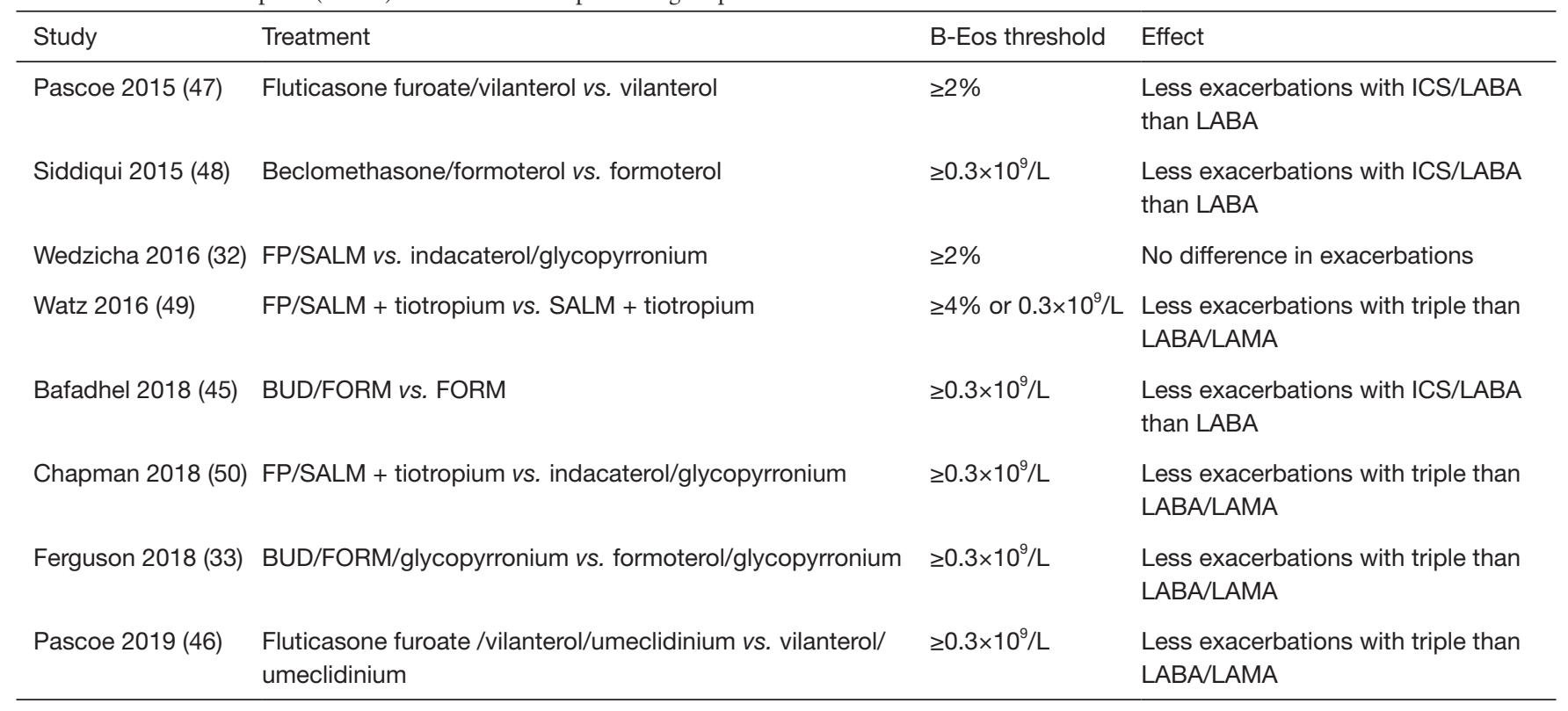

ICS, inhaled corticosteroids; COPD, chronic obstructive pulmonary disease; LABA, long acting 32 -agonists; LAMA, long-acting muscarinic antagonist; FP, fluticasone propionate; SALM, salmeterol; BUD, budesonide; FORM, formoterol.

Recently fixed triple combinations have been introduced. In three studies, patients on fixed triple compounds had a lower incidence of exacerbations than patients using LABA/ LAMA or ICS/LABA $(14,33,38)$. In one of these studies, triple therapy was also shown to increase health-related quality of life and decrease dyspnoea to a greater extent than LABA/LAMA or ICS/LABA treatment (14).

\section{Asthma COPD overlap (ACO)}

Many COPD patients have concomitant asthma and the term ACO has been introduced to cover this condition $(39,40)$. Patients with ACO have more symptoms and more exacerbations than patient with only asthma or COPD $(39,41)$. There is lack of studies evaluating treatment of ACO, but it is generally recommended that this treatment should include ICS $(42,43)$.

\section{Eosinophils}

Several studies have shown that B-Eos predicts whether a patient will be benefit from talking ICS in combination with LABA or LABA/LAMA compared with bronchodilators alone $(33,44-50)$ (Table 1). Different thresholds have been used and in some studies B-Eos have been expressed as percentage of the total leukocyte count, whereas in the more recent studies the number of eosinophils per volume blood has been used. In all studies the benefit of using ICS in combination with long acting bronchodilators increases in comparison with only using long acting bronchodilators with the number of eosinophils, so the context of threshold levels is relative. Based on the studies above, GOLD strongly support the use of ICS in combination with LABA or LABA/LAMA in COPD patients with frequently exacerbation and B-Eos $\geq 0.3 \times 10^{9} / \mathrm{L}$, consider use of ICS in combination with LABA or LABA/LAMA when B-Eos are between $(0.1-0.3) \times 10^{9} / \mathrm{L}$ while ICS is not at all recommended if B-Eos is $<0.1 \times 10^{9} / \mathrm{L}(5)$. In one study, the risk of pneumonia was higher in COPD patient with B-Eos $<0.1 \times 10^{9} / \mathrm{L}(51)$. The risk was further increased if these patients were using ICS.

\section{Effect of ICS on lung function decline}

COPD is characterised by a faster than normal decline in lung function (52). There were expectations that treatment with ICS would slow the speed of this decline. Several early studies failed to show this (53-55). In some more recent studies, however, a small positive effect on lung function decline with ICS (8-13 mL/years) has been reported $(56,57)$. In one study, the effect of ICS on lung function decline was only found in COPD patients with B-Eos $\geq 2 \%$ (58). 
Table 2 Studies assessing the effect of ICS on mortality

\begin{tabular}{llll}
\hline Study & Treatment & Follow-up time & Effect \\
\hline Soriano 2002 (59) & FP/SALM vs. no ICS or LABA, retrospective & 3 years & Better survival for FP/SALM, P=0.0008 \\
Calverley 2007 (29) & FP/SALM vs. placebo, RCT & 3 years & $\begin{array}{l}\text { Trend towards better survival with FP/ } \\
\text { SALM, P=0.052 }\end{array}$ \\
Wedzicha 2008 (30) & FP/SALM vs. tiotropium, RCT & 1 year & Better survival with FP/SALM, P=0.038 \\
Halpin 2008 (60) & BUD vs. non-BUD, pooled analyses of two RCTs & 1 year & Better survival for BUD, P=0.036 \\
Vestbo 2016 (56) & Fluticasone furoate/vilanterol vs. placebo, RCT & 3 years & No difference, P=0.137 \\
Lipson 2018 (14) & $\begin{array}{l}\text { Fluticasone furoate/vilanterol/umeclidinium vs. } \\
\text { vilanterol/umeclidinium }\end{array}$ & 1 year & $\begin{array}{l}\text { Better survival for the two treatments } \\
\text { containing fluticasone furoate than for } \\
\end{array}$ \\
& $\begin{array}{l}\text { Fluticasone furoate/vilanterol vs. vilanterol/ } \\
\text { umeclidinium, RCT }\end{array}$ & & vilanterol/umeclidinium, P=0.01
\end{tabular}

ICS, inhaled corticosteroids; FP, fluticasone propionate; SALM, salmeterol; LABA, long acting $\beta 2$-agonists; RCT , randomised control trial; BUD, budesonide.

\section{Effect of ICS on mortality}

Studies investigating whether treatment with ICS influences all-cause mortality are summarized in Table 2. In a retrospective study, based on primary care data from the United Kingdom Soriano and co-workers found that patients treated with FP/SALM and FP had lower mortality than matched patients that were not on ICS and LABA (59). In the only RCT where mortality was the primary outcome variable, patients treated with FP/SALM had an almost statistically significant better survival than patients on placebo did (P=0.052) (29). In another study, FP/SALM treated patients had better survival than patients treated with tiotropium (30). A pooled analysis of two RCTs showed that BUD treated patients had better survival than non-BUD treated patients (60). In a RCT that included patients that had both COPD and cardiovascular disease, no difference was found in survival when comparing those with fluticasone furoate/vilanterol with those with placebo (56). Finally, in the IMPACT study, patients with triple therapy (fluticasone furoate/vilanterol/umeclidinium) and ICS-LABA (fluticasone furoate/vilanterol) had less all-cause mortality than those treated with LABA/LAMA (vilanterol/umeclidinium) (14).

\section{Comparison of different ICS}

There are many ICSs to choose between in the treatment of COPD. There are, however a lack of RCTs that compare these different ICSs in COPD. Fortunately, there are data available from observations studies. Most of these studies have compare the effectiveness and safety of BUD with that of FP. Unfortunately, there are only a few studies that compare these two ICS with other ICS such as fluticasone furoate or beclomethasone.

\section{Effect on exacerbations}

Four retrospective studies have found a lower exacerbation rate in COPD patients treated with BUD/FORM compared to those treated with FP/SALM (Table 3). The first of these studies was a Canadian study were approximately 1,300 patients treated with BUD/FORM was matched with the same number of patients treated with FP/SALM. The study period was one year (61). In the study, the risk of all kinds of exacerbations was $15-39 \%$ lower in patients using BUD/FORM than in those using FP/SALM. Similar results were found in studies from Sweden (41), Italy (63) and Taiwan (64). The only study where no difference was found between BUD/FORM and FP/ SALM was from the United States and its possible that this was related to low adherence to prescribed medication in that study (62). No difference in acute severe exacerbations was found between FP/SALM and beclomethasone/FORM in an observational study from Taiwan (65).

\section{Risk of pneumonia}

In the PATHOS study, data from electronic medical records were merged with Swedish national registry data. COPD patients on FP/SALM had more pneumonia events than matched patients with BUD/FORM [rate ratio (95\% CI) $1.73(1.57-1.90)]$ (66). Similar results were found in a study from Taiwan (64). Use of FP was associated with 
Table 3 Studies comparing the effect of different ICS-LABA combinations on exacerbations

\begin{tabular}{|c|c|c|c|}
\hline Study & Treatment & Follow-up time & Effect \\
\hline Blais 2010 (61) & & & Adjusted RR 0.75 (0.58-0.97) for ED visit \\
\hline \multirow[t]{2}{*}{ Larson 2013 (41) } & BUD/FORM vs. FP/SALM & Up to 10 years & Less exacerbations with BUD/FORM \\
\hline & & & Adjusted RR 0.74 (0.69-0.79) for all exacerbations \\
\hline Kern 2015 (62) & & & Adjusted RR 1.11 (0.97-1.28) for ED visit \\
\hline \multirow[t]{2}{*}{ Perrone 2016 (63) } & BUD/FORM vs. FP/SALM & Up to 3 years & Less exacerbations with BUD/FORM \\
\hline & & & IRR 0.89 (0.87-0.92) for OCS prescriptions \\
\hline Yang 2017 (64) & BUD/FORM vs. FP/SALM & Up to 13 years & Less exacerbations with BUD/FORM \\
\hline
\end{tabular}

ICS, inhaled corticosteroids; LABA, long acting $\beta 2$-agonists; BUD, budesonide; FORM, formoterol; FP, fluticasone propionate; SALM, salmeterol; RR , risk ratio; ED, emergency department; IRR, incidence rate ratio; OCS, oral corticosteroids.

highly increased risk of pneumonia in a large Canadian database study [rate ratio (95\% CI) $2.01(1.93-2.10)$ ], whereas the association was lower for the use of BUD [rate ratio (95\% CI) 1.17 (1.09-1.26)] (67). In an analysis of the UPLIFT trial, the incidence of pneumonia was higher in patients using FP than those using other ICS (68). Finally, a tendency to a higher risk of pneumonia was found in patients treated with FP/SALM than those using BUD/ FORM in an analysis of hospitalised COPD patients in Japan (69). The difference between FP and BUD in the association to pneumonia has also been highlighted in meta-analyses $(23,24,70)$. In one of these analyses, Kew et al. found that the risk of any pneumonia event was higher with fluticasone than with BUD (OR 1.86, 95\% CI: 1.04 to 3.34). However, they also stated that this finding should be interpreted with caution because of possible differences in the assignment of pneumonia between the studies (70).

A higher risk of pneumonia in patients using fluticasone furoate have been found in several studies $(14,71)$. There are also results from a RCT comparing treatment with fluticasone furoate/vilanterol/umeclidinium with BUD/ FORM that showed a higher accumulated prevalence of pneumonia in the group with fluticasone furoate compared to the group treated with BUD/FORM during 24 weeks (72). However, no difference in the incidence of pneumonia between the two treatments was found during the extended follow up period (weeks 25 to 52 ) which about half of the study population went through. In the study by Suissa et al. the risk for of pneumonia for patients using beclomethasone, flunisolide or triamcinolone was in between that of the risk of $\mathrm{FP}$ and BUD [rate ratio (95\% CI) 1.41 (1.33-1.51)] (67). A recent observational study from Taiwan found that the risk of pneumonia was lower in patients treated with beclomethasone/FORM compared to treatment with FP/SALM, but this difference became non-significant after adjusting for daily ICS dose (65). It should be noted, that despite data supporting a difference between FP and BUD when it comes to the risk of pneumonia the European Medical Agency found no evidence of a difference between different ICS drugs in a review from 2016 (73).

\section{Benefits of using ICS versus side effects}

Using ICS in combination with LABA and LABA/LAMA have clinical important beneficial effects and negative side effects. It is therefore important to decide if the benefits outweigh the negative effects. In the PATHOS study, the incidence of exacerbations was about ten times higher than the incidence of pneumonia $(41,66)$. This indicates that the preventive effect of exacerbations is more important than the risk increase in pneumonia. On the other hand, Suissa and co-workers calculated number needed to treat (NNT) for exacerbations and pneumonia (74) based on a 1-year trial of FP/SALM vs. SALM (15). They found that the NNT for avoiding one exacerbation during one year of treatment with FP/SALM was relatively similar as the NNT for inducing one pneumonia (14 vs. 20) (74). In a 
review from 2018, Agusti et al. conclude that that some COPD patients benefit from the addition of ICS to longacting bronchodilator treatment whereas others do not and that the risk/benefit ratio of adding ICS has to be carefully considered in each individual patient (43). Factors that support using ICS are repeated exacerbations, B-Eos $\geq 0.3 \times 10^{9} / \mathrm{L}$ and concomitant asthma, whereas repeated pneumonia, history of mycobacterial infections and B-Eos $<0.1 \times 10^{9} / \mathrm{L}$ support avoiding to use ICS (43).

\section{Conclusions}

ICS together with LABA or LABA/LAMA reduces the risk of exacerbations in COPD. ICS, however, do have side effects where an increased risk of pneumonia is probably the most clinically important one. The indication of using ICS in COPD is stronger if the patient has concomitant asthma and or increased B-Eos levels. Apart from reducing the risk of exacerbations, there is also data indicating that ICS has a small but significant positive effect on lung function decline and mortality. Overall the benefits of ICS in treating COPD continue to outweigh their risks, however, the choice of ICS matters with data from observational studies showing a better effect-safety profile with BUD compared to FP whereas it is not possible to make benefit-risk comparisons between the other licensed ICSs.

\section{Acknowledgments}

Funding: None.

\section{Footnote}

Conflicts of Interest: The author has received payments for educational activities from AstraZeneca, Boehringer Ingelheim, Chiesi, GlaxoSmithKline, Novartis and Teva, and has served on advisory boards arranged by AstraZeneca, Boehringer Ingelheim, Chiesi, GlaxoSmithKline, Novartis and Teva.

Ethical Statement: The author is accountable for all aspects of the work in ensuring that questions related to the accuracy or integrity of any part of the work are appropriately investigated and resolved.

Open Access Statement: This is an Open Access article distributed in accordance with the Creative Commons Attribution-NonCommercial-NoDerivs 4.0 International
License (CC BY-NC-ND 4.0), which permits the noncommercial replication and distribution of the article with the strict proviso that no changes or edits are made and the original work is properly cited (including links to both the formal publication through the relevant DOI and the license). See: https://creativecommons.org/licenses/by-nc-nd/4.0/.

\section{References}

1. Janson C, Marks G, Buist S, et al. The impact of COPD on health status: findings from the BOLD study. Eur Respir J 2013;42:1472-83.

2. Lisspers K, Larsson K, Johansson G, et al. Economic burden of COPD in a Swedish cohort: the ARCTIC study. Int J Chron Obstruct Pulmon Dis 2018;13:275-85.

3. Lozano R, Naghavi M, Foreman K, et al. Global and regional mortality from 235 causes of death for 20 age groups in 1990 and 2010: a systematic analysis for the Global Burden of Disease Study 2010. Lancet 2012;380:2095-128. Erratum in: Lancet 2013;381:628. AlMazroa, Mohammad A [added]; Memish, Ziad A [added].

4. Ställberg B, Janson C, Johansson G, et al. Management, morbidity and mortality of COPD during an 11-year period: an observational retrospective epidemiological register study in Sweden (PATHOS). Prim Care Respir J 2014;23:38-45.

5. Singh D, Agusti A, Anzueto A, et al. Global Strategy for the Diagnosis, Management, and Prevention of Chronic Obstructive Lung Disease: the GOLD science committee report 2019. Eur Respir J 2019. doi: 10.1183/13993003.00164-2019.

6. Buist AS, McBurnie MA, Vollmer WM, et al. International variation in the prevalence of COPD (The BOLD Study): a population-based prevalence study. Lancet 2007;370:741-50.

7. Lamprecht B, Soriano JB, Studnicka M, et al. Determinants of underdiagnosis of COPD in national and international surveys. Chest 2015;148:971-85.

8. Sator L, Horner A, Studnicka M, et al. Overdiagnosis of COPD in Subjects With Unobstructed Spirometry: A BOLD Analysis. Chest 2019;156:277-88.

9. Wang $\mathrm{Y}, \mathrm{Xu}$ J, Meng $\mathrm{Y}$, et al. Role of inflammatory cells in airway remodeling in COPD. Int J Chron Obstruct Pulmon Dis 2018;13:3341-48.

10. Tashkin DP, Wechsler ME. Role of eosinophils in airway inflammation of chronic obstructive pulmonary disease. Int J Chron Obstruct Pulmon Dis 2018;13:335-49.

11. "Global strategy for asthma management and prevention: GINA executive summary." E.D. Bateman, S.S. Hurd, 
P.J. Barnes, J. Bousquet, J.M. Drazen, J.M. FitzGerald, P. Gibson, K. Ohta, P. O'Byrne, S.E. Pedersen, E. Pizzichini, S.D. Sullivan, S.E. Wenzel and H.J. Zar. Eur Respir J 2008; 31: 143-178. Eur Respir J 2018. doi: 10.1183/13993003.51387-2007.

12. Agusti A, Fabbri LM. Inhaled steroids in COPD: when should they be used? Lancet Respir Med 2014;2:869-71.

13. Calverley PM, Boonsawat W, Cseke Z, et al. Maintenance therapy with budesonide and formoterol in chronic obstructive pulmonary disease. Eur Respir J 2003;22:912-9.

14. Lipson DA, Barnhart F, Brealey N, et al. Once-Daily Single-Inhaler Triple versus Dual Therapy in Patients with COPD. N Engl J Med 2018;378:1671-80.

15. Anzueto A, Ferguson GT, Feldman G, et al. Effect of fluticasone propionate/salmeterol (250/50) on COPD exacerbations and impact on patient outcomes. COPD 2009;6:320-9.

16. Tashkin DP, Rennard SI, Martin P, et al. Efficacy and safety of budesonide and formoterol in one pressurized metereddose inhaler in patients with moderate to very severe chronic obstructive pulmonary disease: results of a 6-month randomized clinical trial. Drugs 2008;68:1975-2000.

17. Löfdahl CG, Postma DS, Pride NB, et al. Possible protection by inhaled budesonide against ischaemic cardiac events in mild COPD. Eur Respir J 2007;29:1115-9.

18. Sandelin M, Mindus S, Thuresson M, et al. Factors associated with lung cancer in COPD patients. Int J Chron Obstruct Pulmon Dis 2018;13:1833-9.

19. Raymakers AJN, Sadatsafavi M, Sin DD, et al. Inhaled corticosteroids and the risk of lung cancer in COPD: a population-based cohort study. Eur Respir J 2019. doi: 10.1183/13993003.01257-2018.

20. Price D, Yawn B, Brusselle G, et al. Risk-to-benefit ratio of inhaled corticosteroids in patients with COPD. Prim Care Respir J 2013;22:92-100.

21. Jenkins CR, Jones PW, Calverley PM, et al. Efficacy of salmeterol/fluticasone propionate by GOLD stage of chronic obstructive pulmonary disease: analysis from the randomised, placebo-controlled TORCH study. Respir Res 2009;10:59.

22. Janson C, Johansson G, Stallberg B, et al. Identifying the associated risks of pneumonia in COPD patients: ARCTIC an observational study. Respir Res 2018;19:172.

23. Festic E, Bansal V, Gupta E, et al. Association of Inhaled Corticosteroids with Incident Pneumonia and Mortality in COPD Patients; Systematic Review and Meta-Analysis. COPD 2016;13:312-26.

24. Yang M, Du Y, Chen H, et al. Inhaled corticosteroids and risk of pneumonia in patients with chronic obstructive pulmonary disease: A meta-analysis of randomized controlled trials. Int Immunopharmacol 2019;77:105950.

25. Vogelmeier C, Hederer B, Glaab T, et al. Tiotropium versus salmeterol for the prevention of exacerbations of COPD. N Engl J Med 2011;364:1093-103.

26. Wedzicha JA, Decramer M, Ficker JH, et al. Analysis of chronic obstructive pulmonary disease exacerbations with the dual bronchodilator QVA149 compared with glycopyrronium and tiotropium (SPARK): a randomised, double-blind, parallel-group study. Lancet Respir Med 2013;1:199-209.

27. Donohue JF. Another Choice for Prevention of COPD Exacerbations. N Engl J Med 2016;374:2284-6.

28. Szafranski W, Cukier A, Ramirez A, et al. Efficacy and safety of budesonide/formoterol in the management of chronic obstructive pulmonary disease. Eur Respir J 2003;21:74-81.

29. Calverley PM, Anderson JA, Celli B, et al. Salmeterol and fluticasone propionate and survival in chronic obstructive pulmonary disease. N Engl J Med 2007;356:775-89.

30. Wedzicha JA, Calverley PM, Seemungal TA, et al. The prevention of chronic obstructive pulmonary disease exacerbations by salmeterol/fluticasone propionate or tiotropium bromide. Am J Respir Crit Care Med 2008;177:19-26.

31. Zhong N, Wang C, Zhou X, et al. LANTERN: a randomized study of QVA149 versus salmeterol/fluticasone combination in patients with COPD. Int J Chron Obstruct Pulmon Dis 2015;10:1015-26.

32. Wedzicha JA, Banerji D, Chapman KR, et al. IndacaterolGlycopyrronium versus Salmeterol-Fluticasone for COPD. N Engl J Med 2016;374:2222-34.

33. Ferguson GT, Rabe KF, Martinez FJ, et al. Triple therapy with budesonide/glycopyrrolate/formoterol fumarate with co-suspension delivery technology versus dual therapies in chronic obstructive pulmonary disease (KRONOS): a double-blind, parallel-group, multicentre, phase 3 randomised controlled trial. Lancet Respir Med 2018;6:747-58.

34. Welte T, Miravitlles M, Hernandez P, et al. Efficacy and Tolerability of Budesonide/Formoterol Added to Tiotropium in Patients with Chronic Obstructive Pulmonary Disease. Am J Respir Crit Care Med 2009; 180:741-50.

35. Lee SD, Xie CM, Yunus F, et al. Efficacy and tolerability of budesonide/formoterol added to tiotropium compared with tiotropium alone in patients with severe or very 
severe COPD: A randomized, multicentre study in East Asia. Respirology 2016;21:119-27.

36. Aaron SD, Vandemheen KL, Fergusson D, et al. Tiotropium in combination with placebo, salmeterol, or fluticasone-salmeterol for treatment of chronic obstructive pulmonary disease: a randomized trial. Ann Intern Med 2007;146:545-55.

37. Jung KS, Park HY, Park SY, et al. Comparison of tiotropium plus fluticasone propionate/salmeterol with tiotropium in COPD: a randomized controlled study. Respir Med 2012;106:382-9.

38. Papi A, Vestbo J, Fabbri L, et al. Extrafine inhaled triple therapy versus dual bronchodilator therapy in chronic obstructive pulmonary disease (TRIBUTE): a doubleblind, parallel group, randomised controlled trial. Lancet 2018;391:1076-84.

39. Mindus S, Malinovschi A, Ekerljung L, et al. Asthma and COPD overlap (ACO) is related to a high burden of sleep disturbance and respiratory symptoms: Results from the RHINE and Swedish GA2LEN surveys. PLoS One 2018; 13:e195055.

40. Lisspers K, Johansson G, Jansson C, et al. Improvement in COPD management by access to asthma/COPD clinics in primary care: data from the observational PATHOS study. Respir Med 2014;108:1345-54.

41. Larsson K, Janson C, Lisspers K, et al. Combination of budesonide/formoterol more effective than fluticasone/ salmeterol in preventing exacerbations in chronic obstructive pulmonary disease: the PATHOS study. J Intern Med 2013;273:584-94.

42. Maselli DJ, Hanania NA. Management of asthma COPD overlap. Ann Allergy Asthma Immunol 2019;123:335-44.

43. Agusti A, Fabbri LM, Singh D, et al. Inhaled corticosteroids in COPD: friend or foe? Eur Respir J 2018;52:1801219.

44. Pascoe S, Locantore N, Dransfield MT, et al. Blood eosinophil counts, exacerbations, and response to the addition of inhaled fluticasone furoate to vilanterol in patients with chronic obstructive pulmonary disease: a secondary analysis of data from two parallel randomised controlled trials. Lancet Respir Med 2015;3:435-42.

45. Bafadhel M, Peterson S, De Blas MA, et al. Predictors of exacerbation risk and response to budesonide in patients with chronic obstructive pulmonary disease: a post-hoc analysis of three randomised trials. Lancet Respir Med 2018;6:117-26.

46. Pascoe S, Barnes N, Brusselle G, et al. Blood eosinophils and treatment response with triple and dual combination therapy in chronic obstructive pulmonary disease: analysis of the IMPACT trial. Lancet Respir Med 2019;7:745-56.

47. Pascoe S, Locantore N, Dransfield MT, et al. Blood eosinophil counts as markers of response to inhaled corticosteroids in COPD?--Authors' reply. Lancet Respir Med 2015;3:e27.

48. Siddiqui SH, Guasconi A, Vestbo J, et al. Blood Eosinophils: A Biomarker of Response to Extrafine Beclomethasone/Formoterol in Chronic Obstructive Pulmonary Disease. Am J Respir Crit Care Med 2015;192:523-5.

49. Watz H, Tetzlaff K, Wouters EF, et al. Blood eosinophil count and exacerbations in severe chronic obstructive pulmonary disease after withdrawal of inhaled corticosteroids: a post-hoc analysis of the WISDOM trial. Lancet Respir Med 2016;4:390-8.

50. Chapman KR, Hurst JR, Frent SM, et al. LongTerm Triple Therapy De-escalation to Indacaterol/ Glycopyrronium in Patients with Chronic Obstructive Pulmonary Disease (SUNSET): A Randomized, DoubleBlind, Triple-Dummy Clinical Trial. Am J Respir Crit Care Med 2018;198:329-39.

51. Martinez-Garcia MA, Faner R, Oscullo G, et al. Inhaled Steroids, Circulating Eosinophils, Chronic Airway Infection and Pneumonia Risk in Chronic Obstructive Pulmonary Disease: A Network Analysis. Am J Respir Crit Care Med 2020. [Epub ahead of print].

52. Fletcher C, Peto R. The natural history of chronic airflow obstruction. Br Med J 1977;1:1645-8.

53. Pauwels RA, Lofdahl CG, Laitinen LA, et al. Longterm treatment with inhaled budesonide in persons with mild chronic obstructive pulmonary disease who continue smoking. European Respiratory Society Study on Chronic Obstructive Pulmonary Disease. N Engl J Med 1999;340:1948-53.

54. Vestbo J, Sorensen T, Lange P, et al. Long-term effect of inhaled budesonide in mild and moderate chronic obstructive pulmonary disease: a randomised controlled trial. Lancet 1999;353:1819-23.

55. Burge PS, Calverley PM, Jones PW, et al. Randomised, double blind, placebo controlled study of fluticasone propionate in patients with moderate to severe chronic obstructive pulmonary disease: the ISOLDE trial. BMJ 2000;320:1297-303.

56. Vestbo J, Anderson JA, Brook RD, et al. Fluticasone furoate and vilanterol and survival in chronic obstructive pulmonary disease with heightened cardiovascular risk (SUMMIT): a double-blind randomised controlled trial. 
Lancet 2016;387:1817-26.

57. Celli BR, Thomas NE, Anderson JA, et al. Effect of pharmacotherapy on rate of decline of lung function in chronic obstructive pulmonary disease: results from the TORCH study. Am J Respir Crit Care Med 2008;178:332-8.

58. Barnes NC, Sharma R, Lettis S, et al. Blood eosinophils as a marker of response to inhaled corticosteroids in COPD. Eur Respir J 2016;47:1374-82.

59. Soriano JB, Vestbo J, Pride NB, et al. Survival in COPD patients after regular use of fluticasone propionate and salmeterol in general practice. Eur Respir J 2002;20:819-25.

60. Halpin DM, Peterson S, Larsson TP, et al. Identifying COPD patients at increased risk of mortality: predictive value of clinical study baseline data. Respir Med 2008;102:1615-24.

61. Blais L, Forget A, Ramachandran S. Relative effectiveness of budesonide/formoterol and fluticasone propionate/ salmeterol in a 1-year, population-based, matched cohort study of patients with chronic obstructive pulmonary disease (COPD): Effect on COPD-related exacerbations, emergency department visits and hospitalizations, medication utilization, and treatment adherence. Clin Ther 2010;32:1320-8.

62. Kern DM, Davis J, Williams SA, et al. Comparative effectiveness of budesonide/formoterol combination and fluticasone/salmeterol combination among chronic obstructive pulmonary disease patients new to controller treatment: a US administrative claims database study. Respir Res 2015;16:52.

63. Perrone V, Sangiorgi D, Buda S, et al. Comparative analysis of budesonide/formoterol and fluticasone/ salmeterol combinations in COPD patients: findings from a real-world analysis in an Italian setting. Int J Chron Obstruct Pulmon Dis 2016;11:2749-55.

64. Yang HH, Lai CC, Wang YH, et al. Severe exacerbation and pneumonia in COPD patients treated with fixed combinations of inhaled corticosteroid and longacting beta2 agonist. Int $\mathrm{J}$ Chron Obstruct Pulmon Dis 2017;12:2477-85.

65. Chang TY, Chien JY, Wu CH, et al. Comparative Safety

Cite this article as: Janson C. Treatment with inhaled corticosteroids in chronic obstructive pulmonary disease. J Thorac Dis 2020;12(4):1561-1569. doi: 10.21037/jtd.2020.02.51 and Effectiveness of Inhaled Corticosteroid and LongActing 32 -Agonist Combinations in Patients With COPD. Chest 2019. [Epub ahead of print].

66. Janson C, Larsson K, Lisspers KH, et al. Pneumonia and pneumonia related mortality in patients with COPD treated with fixed combinations of inhaled corticosteroid and long acting beta2 agonist: observational matched cohort study (PATHOS). BMJ 2013;346:f3306.

67. Suissa S, Patenaude V, Lapi F, et al. Inhaled corticosteroids in COPD and the risk of serious pneumonia. Thorax 2013;68:1029-36.

68. Morjaria JB, Rigby A, Morice AH. Inhaled Corticosteroid use and the Risk of Pneumonia and COPD Exacerbations in the UPLIFT Study. Lung 2017;195:281-8.

69. Hirano R, Fujita M, Matsumoto T, et al. Inhaled corticosteroids might not increase the risk of pneumonia in patients with chronic obstructive pulmonary disease in Japan. Int J Chron Obstruct Pulmon Dis 2018;13:3503-9.

70. Kew KM, Seniukovich A. Inhaled steroids and risk of pneumonia for chronic obstructive pulmonary disease. Cochrane Database Syst Rev 2014;(3):CD010115.

71. Rodrigo GJ, Neffen H. A systematic review with metaanalysis of fluticasone furoate/vilanterol combination for the treatment of stable COPD. Pulm Pharmacol Ther 2017;42:1-6.

72. Lipson DA, Barnacle H, Birk R, et al. FULFIL Trial: Once-Daily Triple Therapy for Patients with Chronic Obstructive Pulmonary Disease. Am J Respir Crit Care Med 2017;196:438-46.

73. European Medical Agency: EMA completes review of inhaled corticosteroids for chronic obstructive pulmonary disease. Review finds no differences between products in risk of pneumonia. 2016. Available online: http://www.ema.europa.eu/ema/index.jsp? curl=pages/ news_and_events/news/2016/04/news_detail_002521. jsp\&mid=WC0b01ac058004d5c1. Data last accessed 6 February 2020.

74. Suissa S. Number needed to treat in COPD: exacerbations versus pneumonias. Thorax 2013;68:540-3. 